\title{
Assessment of the Therapeutic Potential of Epigallocatechin Gallate and/or Metformin on Oral Squamous Cell Carcinoma
}

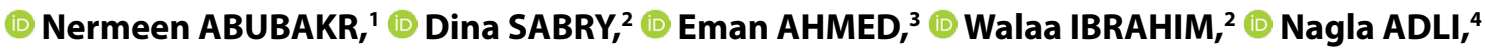 \\ (i) Amany NASR, ${ }^{3}$ (D) Nehal Abd-El HAMEED 5 \\ 'Department of Oral Biology, Cairo University, Faculty of Dentistry, Giza-Egypt \\ ${ }^{2}$ Department of Medical Biochemistry and Molecular Biology, Cairo University, Faculty of Medicine, Giza-Egypt \\ ${ }^{3}$ Department of Pharmacology, Fayoum University, Faculty of Medicine, Fayoum-Egypt \\ ${ }^{4}$ Department of Medical Biochemistry and Molecular Biology, Benisweif University, Faculty of Medicine, Benisweif-Egypt \\ ${ }^{5}$ Department of Clinical Pathology, Cairo University, Faculty of Medicine, Giza-Egypt
}

\begin{abstract}
OBJECTIVE
Squamous cell carcinoma is a prevalent tumor in the head and neck region. Current treatments have low survival rates. Therefore, physicians are seeking alternative therapies. This work compared the effects of Epigallocatechin-3-gallate (EGCG), metformin and a combination of both on oral squamous cell carcinoma.
\end{abstract}

\section{METHODS}

This study was performed on human epithelial type 2 (Hep2) cells. Cell viability was estimated by MTT assay. Gene expression of platelet-derived growth factor, interleukin 6, caspase 3 and survivin was evaluated by a real-time polymerase chain reaction. Reactive oxygen species (ROS) and vascular endothelial growth factor were assessed by ELISA.

\section{RESULTS}

Results showed that cells treated with metformin showed a notable rise in caspase 3 and a significant decrease in all parameters. EGCG had an insignificant change in all parameters tested except a significant decrease in ROS. A combination of both showed a remarkable elevation in caspase 3 and a more pronounced decrease in all parameters.

\section{CONCLUSION}

It was concluded that EGCG exhibited a synergistic anti-proliferative, anti-angiogenic, pro-apoptotic and antioxidant activity on the Hep2 cell line when combined with metformin.

Keywords: Epigallocatechin-3-gallate; laryngeal cancer; metformin; squamous cell carcinoma. Copyright $\odot$ 2020, Turkish Society for Radiation Oncology

\section{Introduction}

Squamous cell carcinoma is a common malignancy in the head and neck region. It arises most commonly from laryngeal epithelial tissue. Globally, it is prevalent among middle-and old-aged men.[1,2] Despite significant enhancements in carcinoma therapeutics, poor prognosis is still evident.[3]
Dr. Nermeen ABUBAKR

Department of Oral Biology,

Cairo University,

Faculty of Dentistry,

Giza-Egypt

E-mail: nermeen.abubakr@dentistry.cu.edu.eg 
Natural phytochemicals as polyphenols possess chemo-preventive, antioxidant and free-radical scavenging properties. They have been reported to cure several tumors, including oral squamous cell carcinoma (OSCC). [4,5]

Green tea is one of the world's most widely consumed drinks. It is particularly popular in the Far East. Green tea has received considerable attention because of its scientifically proven useful impacts on human wellbeing.[6] The polyphenols present in green tea were proved to inhibit cancer cell growth, survival and metastasis.[7]

Epigallocatechin-3-gallate (EGCG) is the most abundant and most active phenolic constituent of green tea. It has a strong antioxidant, chemo-therapeutic and chemo-pre-ventive properties. $[8,9]$

Metformin is a kind of insulin sensitizer. It is used for the treatment of type II diabetes mellitus (DM). Various studies proved that metformin has a considerable hindering impact on different tumor cells' activity, clone formation and proliferation. However, only few studies reported the suppressing impacts of metformin on human oral squamous carcinoma cells.[10] Among the head and neck cancer patients, patients who took metformin for DM control showed a better overall survival rates for laryngeal cancer.[11]

As a result of the increased incidence of squamous cell carcinoma in the head and neck region, there is an urge for more experimental studies to discover the anticancer properties of natural phytochemicals to be used as an alternative therapy.

This study aimed to investigate the therapeutic effects of EGCG, metformin and a combination of both on oral squamous cell carcinoma.

\section{Materials and Methods}

\section{Human Epithelial Type 2 (Hep-2) Cell Line}

This study was performed at the Unit of Biochemistry and Molecular Biology at the Medical Biochemistry Department, Faculty of Medicine, Cairo University, Cairo, Egypt. Hep-2 cell line was purchased from Cell Culture Department- VACSERA- EGYPT. Hep-2 cells were imported from the "American Type Culture Collection (ATCC)" in the form of frozen vials, with the passage number "173". Origin species: Homosapiens (Human). Morphology: epithelial-like cells. Hep-2 cell line was grown in a sterile tissue $50 \mathrm{~cm}^{3}$ flask in complete medium containing Dulbecco's modified Eagle's medium (DMEM) supplemented with $10 \%$ fetal bovine serum (FBS) and antibiotics $(100 \mathrm{U} / \mathrm{ml}$ penicillin and
$100 \mathrm{mg} / \mathrm{ml}$ streptomycin) in $95 \%$ air $5 \% \mathrm{CO}_{2}$ incubator at $37^{\circ} \mathrm{C}$. For the cell viability assay, the Hep- 2 cells were cultivated in three 96-well tissue culture plates containing $10^{3}$ cells $/ \mathrm{ml}$ per well. For polymerase chain reaction (PCR), the Hep-2 cells were cultivated in three 24 well tissue culture plates containing $10^{5}$ cells $/ \mathrm{ml}$ per well. EGCG and metformin were purchased from SigmaAldrich Chemical Co., St. Louis, Mo., U.S.A. They were freshly prepared and dissolved in dimethyl sulfoxide (DMSO).

\section{Cell Viability by Methyl Thiazolyltetrazolium (MTT) Assay}

Hep- 2 cells were dispersed at a frequency of 5000 cells into 96 well plates for overnight incubation. Different concentrations of EGCG and Metformin at a dose of 0, $0.01,1,10,100 \mu \mathrm{g} / \mathrm{ml}$ were added to the cells. The Hep2 cells were treated with $10 \mu \mathrm{L}$ of EGCG and Metformin for 24 hours at different doses. MTT $(0.2 \mathrm{mg} / \mathrm{mL})$ was applied to all wells plate for 4 to 6 hours. When purple color was clearly visible, the detergent reagent was added ( $100 \mu \mathrm{l}$ per well) to solubilize the formazan dye. After four hours of incubation, the optical density in each well was measured at 450 using enzyme-linked immunosorbent assay (ELISA) plate reader (Dynatech MRX 5000; Dynex, Chantilly, VA). For every concentration, ten absorbance readings were estimated and the average was calculated. According to MTT results, the half-maximal inhibitory concentration (IC50) for EGCG and Metformin was calculated.

\section{Cell Culture}

Hep-2 cells as laryngeal cancer cell line were grown in Dulbecco's Modified Eagle's Medium (DMEM) and supplemented with $10 \%$ heat-inactivated fetal calf serum and $1 \%$ antimycotic-antibiotic (Gibco, Grand Island, $\mathrm{NY}$ ) at $37^{\circ} \mathrm{C}, 5 \% \mathrm{CO}_{2}$. Cells were categorized into four groups; control cancer untreated cells, cancer cells supplemented with IC50 dose of EGCG $(31.4 \mu \mathrm{g} /$ $\mathrm{ml})$, cancer cells supplemented with IC50 dose of Metformin $(17.57 \mu \mathrm{g} / \mathrm{ml})$ and cancer cells supplemented with IC50 doses of both EGCG and Metformin.

\section{Real-Time Polymerase Chain Reaction (RT-PCR)}

Hep- 2 cells at $1 \times 10^{5}$ cells/well were cultured in a six well culture plate. EGCG and Metformin were added to grown cells, each at corresponding IC50 concentration for 24 and 48 hours. Cells were trypsinized, harvested and centrifuged. The cells' pellets were chilled on ice and were further subjected to ribonucleic acid (RNA) extraction and purification using Thermo Fisher Scien- 
tific Inc. Germany (Gene JET, Kit, \#K0732) following the manufacturer's instructions. Genes expression was examined using real-time PCR (StepOne, version 2.1, Applied biosystem, Foster City, USA). 10 pg of the total RNA from each sample was used for complementary DNA (cDNA) synthesis followed by PCR amplification cycles using SensiFAST ${ }^{\mathrm{Tw}} \mathrm{SYBR}^{\bullet}$ Hi-ROX One-Step Kit, catalog no. PI-50217 V, UK. The thermal cycling profile was 15 minutes at $45^{\circ} \mathrm{C}$ for cDNA synthesis followed by five minutes at $95^{\circ} \mathrm{C}$ for reverse transcriptase inactivation and polymerase activation. PCR amplification 35 cycles were followed, which consisted of 15 seconds DNA denaturation at $95^{\circ} \mathrm{C}, 30$ seconds primers annealing at $60^{\circ} \mathrm{C}$ and 30 seconds at $72{ }^{\circ} \mathrm{C}$ for the extension step. Changes in the expression of each target gene were normalized relative to the mean critical threshold (CT) values of the $\beta$-actin RNA housekeeping gene by the $\Delta \Delta \mathrm{Ct}$ method. Primer sequences for each gene were demonstrated in Table 1.

Reactive Oxygen Species (ROS) and Vascular Endothelial Growth Factor (VEGF) Assessment by Enzyme-Linked Immunosorbent Assay (ELISA)

The conditioned media of cells in all studied groups were collected. VEGF (ng/ml) (SIGMA-ALDRICH, USA) and ROS ( $\mu \mathrm{g} / \mathrm{ml})$ (Amsbio, USA) were assessed in collected cell culture supernatants according to manual instructions.

\section{Statistical Methods}

Data were coded and entered using the statistical package SPSS version 25. Data were presented as mean and standard deviation (SD) values. Comparisons between groups were done using one-way analysis of variance (ANOVA) with multiple comparisons post hoc test. Correlations between quantitative variables were performed using the Pearson correlation coefficient. P-values less than 0.05 were considered as statistically significant.

\section{Results}

\section{Real-Time Polymerase Chain Reaction (RT-PCR) Results}

Quantitative gene expression of platelet-derived growth factor (PDGF) showed a significant decrease $(p<0.05)$ in the metformin and in the EGCG with metformin groups compared to the control and the EGCG groups (Fig. 1a).

Interleukin-6 (IL-6) as an anti-inflammatory cytokine showed a significant decrease $(\mathrm{p}<0.05)$ in the metformin group compared to the control group, with a higher significant decrease in the EGCG and metformin-treated group compared to the control and the EGCG groups (Fig. 1b).

As regarding apoptotic and antiapoptotic markers (Caspase 3 and survivin, respectively), there was a significant increase $(\mathrm{p}<0.05)$ in caspase 3 expression in the groups that were treated with metformin alone and with EGCG and metformin compared to the control group and the EGCG group. Survivin showed a significant decrease $(\mathrm{p}<0.05)$ in the EGCG and metformin group compared to the control and other treated groups with no statistical significance decrease $(\mathrm{p}>0.05)$ in the groups that are either treated with EGCG alone or metformin alone compared to the control group (Fig. 1c, d, respectively).

Table 1 Primers'sequences of all studied genes

Gene symbol

Caspase-3

Survivin

PDGF

IL-6

B-actin
Primer sequence from $5^{\prime}-3^{\prime}$

Gene bank accession number

F:TGACAGCCAGTGAGACTTGG

R: GACTCTAGACGGCATCCAGC

F: AGA ACTGGCCCTTCTTGGAGG

R: CTT TTTATGTTCCTCTATGGGGTC

F: CACACCTCCTCGCTGTAGTATTTA

R: GTTATCGGTGTAAATGTCATCCAA

F: ACTCACCTCTTCAGAACGAATTG

R:CCATCTTTGGAAGGTTCAGGTTG

F: GGCGGCACCACCATGTACCCT

R: AGGGGCCGGACTCGTCATACT
NM004346.3

NG029069.1

AH002928.2

NM000600.4

NM001101.3 


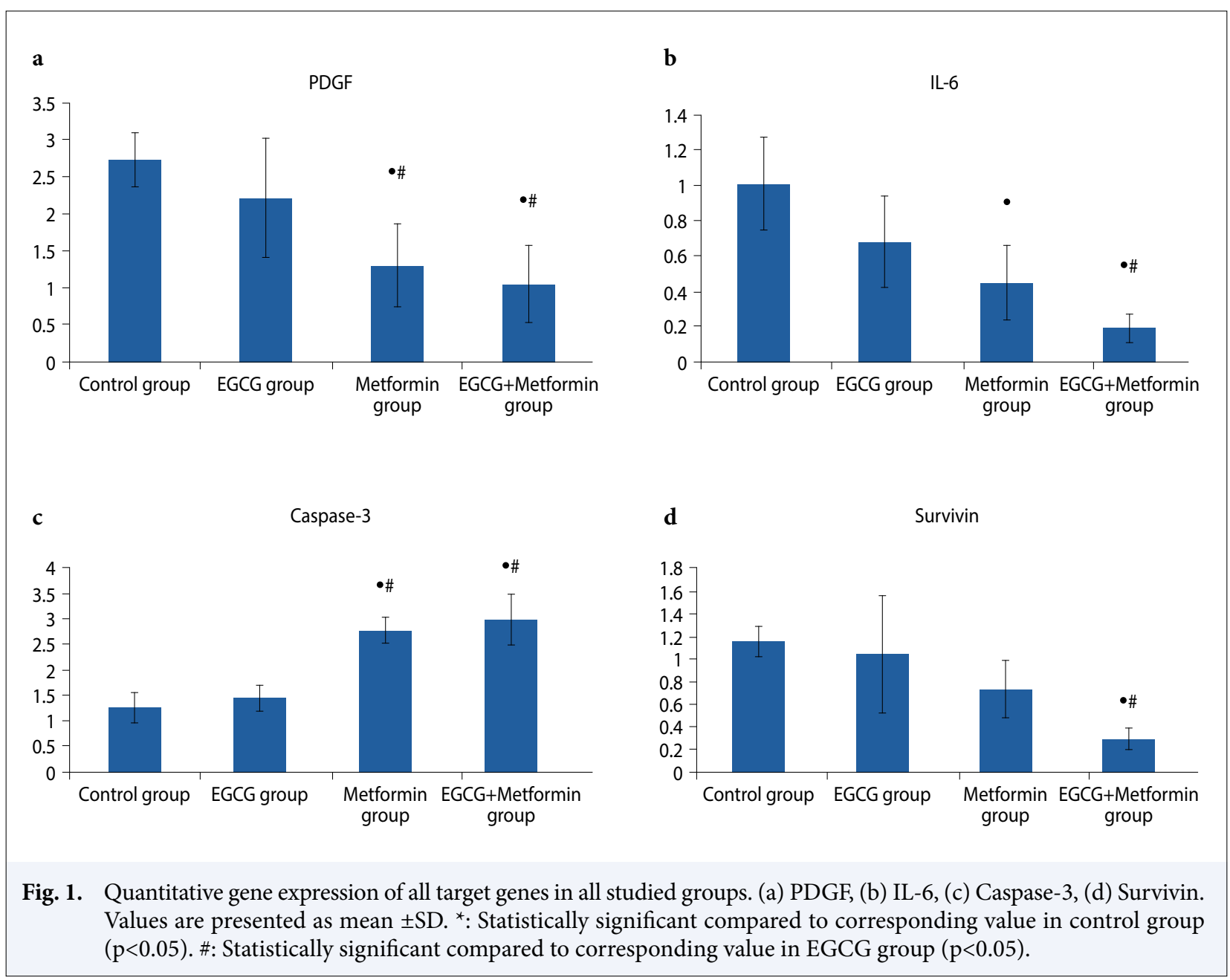

\section{VEGF Assessment by Enzyme-Linked Immunosor- bent Assay (ELISA) Results}

VEGF level was significantly decreased $(p<0.05)$ in the metformin group and in EGCG with metformin group compared to the control group and the EGCG group (Fig. 2a). It showed a significant decrease $(\mathrm{p}<0.05)$ in the EGCG and metformin-treated group compared to all other groups.

\section{Cell Viability by MTT Assay Results}

MTT assay of Hep-2 cells proliferation rate showed a significant decrease in the proliferation rate in the metformin group and in the EGCG with metformin group compared to the control group and the EGCG group $(\mathrm{p}<0.05)$ (Fig. 2b).

As regarding the oxidative stress, ROS level showed a significant decrease in all treated groups compared to the control group $(\mathrm{p}<0.05)$, there was a significant decrease in the EGCG with metformin group compared to the metformin group $(\mathrm{p}<0.05)$ (Fig. $2 \mathrm{c})$.
A significant positive correlation was observed between cell proliferation absorbance and the relative gene expression of all target genes in all studied groups (PDGF, IL-6, Caspase 3 and survivin), ( $r=0.581,0.658$, 0.691, 0.807 respectively), $p<0.001$. (Fig. 3 a-d). Also, there was a significant positive correlation between the cell proliferation absorbance and the VEGF level $(\mathrm{r}=0.729, \mathrm{p}<0.001)$ (Fig. 3e).

Another significant positive correlation was also observed between the ROS level and the relative gene expression of the target genes (PDGF, IL- 6 and survivin) in all studied groups $(\mathrm{r}=0.447,0.563,0.389)(\mathrm{p}<0.05)$. While there was a non-significant positive correlation between ROS level and the relative gene expression of Caspase $3(\mathrm{r}=0.389, \mathrm{p}>0.05)$ (Table 2).

There was also a significant positive correlation between the ROS level and VEGF level $(\mathrm{r}=0.434, \mathrm{p}<0.05)$, but there was a non- significant positive correlation between ROS level and cell proliferation at absorbance $450(\mathrm{r}=0.222, \mathrm{p}>0.05)$ (Table 2). 


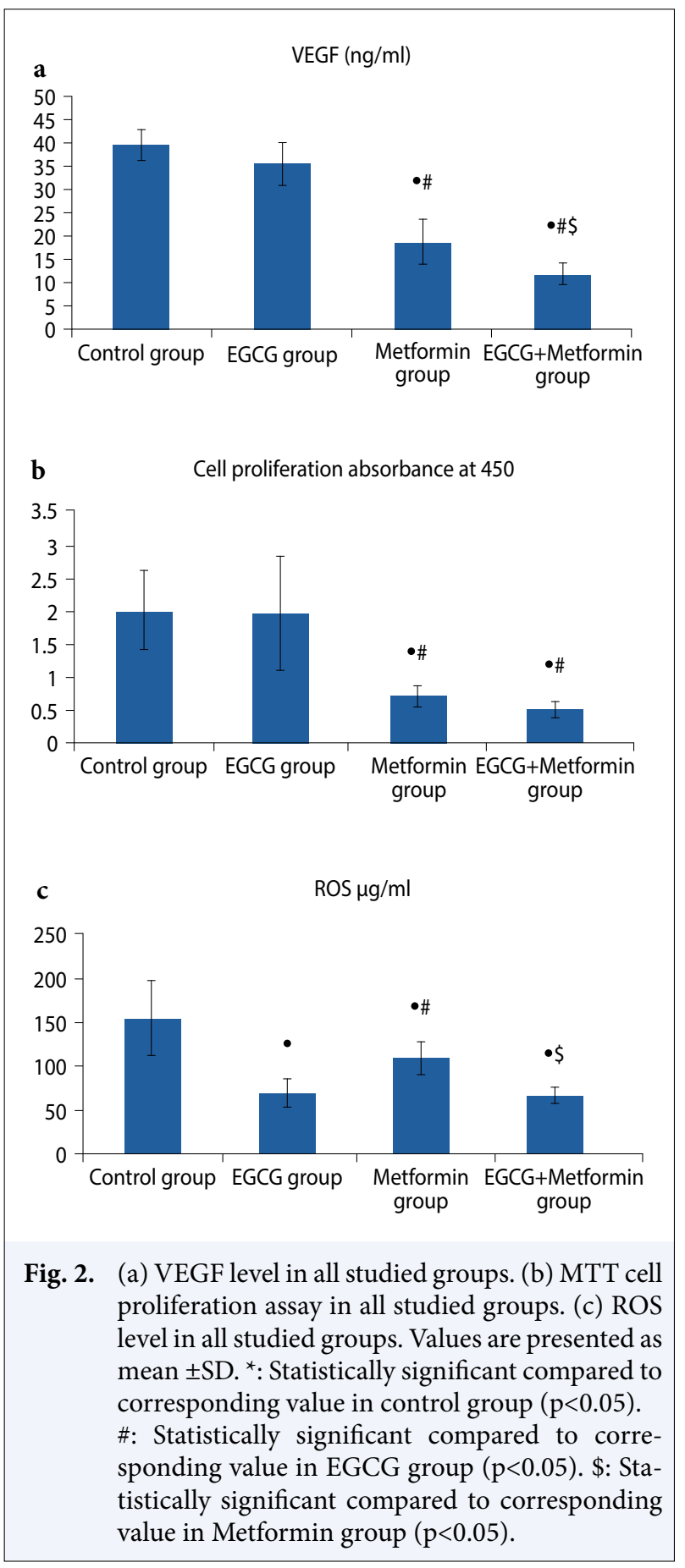

\section{Discussion}

The results of this research showed that metformin has a significant cytotoxic effect on human laryngeal cancer Hep-2 cell line. Metformin inhibited VEGF, PDGF and IL-6. It also decreased ROS production and increased caspase 3 expression. Differently, EGCG only significantly decreased ROS production.

\begin{tabular}{lcc} 
Table 2 & $\begin{array}{c}\text { Correlations between the ROS level and all mea- } \\
\text { sured parameters in all studied groups }\end{array}$ & \multicolumn{3}{c}{ ROS $\mathbf{~} \mathbf{g} / \mathbf{m l}$} \\
\hline PDGF & $\mathrm{R}$ & 0.447 \\
& $\mathrm{p}$ value & $0.017^{*}$ \\
IL-6 & $\mathrm{n}$ & 28 \\
& $\mathrm{R}$ & 0.563 \\
& $\mathrm{p}$ value & $0.002^{*}$ \\
Caspase-3 & $\mathrm{n}$ & 28 \\
& $\mathrm{R}$ & $-0.348-$ \\
& $\mathrm{p}$ value & 0.069 \\
Survivin & $\mathrm{n}$ & 28 \\
& $\mathrm{R}$ & 0.389 \\
& $\mathrm{p}$ value & $0.041^{*}$ \\
VEGF (ng/ml) & $\mathrm{n}$ & 28 \\
& $\mathrm{R}$ & 0.434 \\
& $\mathrm{p}$ value & $0.021^{*}$ \\
Cell proliferation absorbance at 450 & $\mathrm{n}$ & 28 \\
& $\mathrm{R}$ & 0.222 \\
& $\mathrm{p}$ value & 0.256 \\
& $\mathrm{n}$ & 28 \\
\hline
\end{tabular}

Table 2 shows a significant positive correlation between the level of ROS and the relative gene expression of the target genes (PDGF, IL- 6 and survivin) and also between the level of ROS and VEGF level $(p<0.05)$ in all studied groups

These findings are consistent with previous studies where Sikka et al. demonstrated that metformin alone is cytotoxic to head and neck squamous cell carcinoma (HNSCC) cells, reducing cell viability by $>50 \%$ in a dose-dependent manner.[12] In addition, Yasmeen et al. demonstrated that metformin mediates apoptosis by increasing caspase- 3 activity in epithelial ovarian cancer cells and human oral cancer cell line $\mathrm{KB}$, respectively.[13]

The antiangiogenic action of metformin was demonstrated in different in vitro and in vivo models. Metformin reduced proangiogenic factors in polycystic ovarian syndrome. In addition, it decreased VEGF levels in diabetic obese patients.[14] Rattan et al. also proved that metformin suppressed the metastatic spread and angiogenesis of ovarian cancer. It was also shown to hinder the proliferation of tumor cells.[15]

There is a strong association between inflammation and cancer, which is indicated by the high IL- 6 levels in the tumor microenvironment.[16] Results of the present study are in accordance with previous 

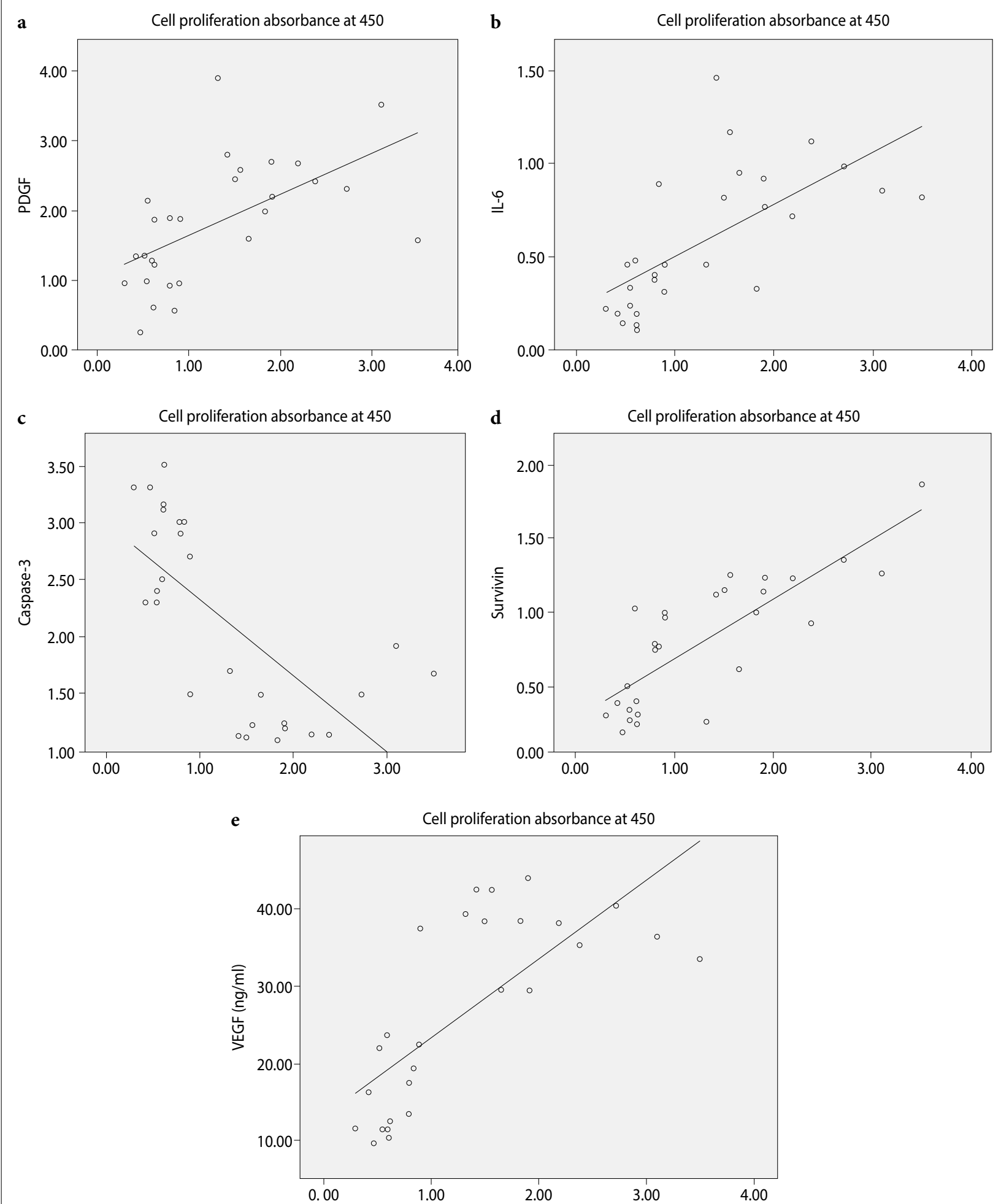

Fig. 3. Correlation between cell proliferation absorbance and the relative gene expression of all target genes in all studied groups. (a) PDGF, (b) IL-6, (c) Caspase-3, (d) Survivin, (e) VEGF. Figures show significant positive correlations between cell proliferation absorbance and the relative gene expression of all target genes (PDGF, IL-6, Caspase-3, Survivin and VEGF) in all studied groups ( $r=0.581,0.658,0.691,0.807,0.434$ respectively), $\mathrm{p}<0.05$. 
studies that demonstrated that metformin was able to hinder pro-inflammatory mediators' expression as interleukin-16 (IL-16) and IL-17. These molecules have a crucial role in tumor growth through suppressing the activity of nuclear factor kappa-light-chain-enhancer of activated B cells (NF-kB).[17,18]

Regarding the effects on reactive oxygen species (ROS) production in the current study, a high ROS level was generated in control Hep-2 cells that decreased significantly in all treated groups. Many previous studies demonstrated the anti-oxidant effects of EGCG and metformin. Murakami et al. reported that EGCG inhibited the cytotoxicity evoked by hydrogen peroxide $\left(\mathrm{H}_{2} \mathrm{O}_{2}\right)$ and elevated the levels of enzymes related to oxidative stress, resulting in an enhanced cellular glutathione (GSH) content in a human liver cancer cell line (HepG2).[19] EGCG possesses a significant antioxidant effect as it contains phenolic groups which upon oxidation can generate quinone. Algire et al. proved that metformin attenuated the paraquat-induced increase in ROS, as well as DNA damage and mutations.[20]

In the current work, the combination of both EGCG and metformin produced more pronounced effects than each drug alone in all tested parameters.

Previous studies suggested that EGCG can synergistically inhibit cancer cells in vitro and in vivo when combined with other dietary agents [21,22] or with chemotherapeutic agents. [23] Combination of EGCG with these molecules can synergistically inhibit cancer cell proliferation, [24,25] induce apoptosis [26] and suppress tumor angiogenesis and growth.[27] Yu et al. demonstrated that metformin enhanced the cytotoxic effect of EGCG and EGCG-induced apoptosis rate in A549 cells (adeno-carcinomic human alveolar basal epithelial cells) that are known to be resistant to EGCG. They assumed that treatment with metformin decreased expression of the NF-E2-related factor 2 (Nrf2)/heme oxygenase-1 (HO-1) signaling pathway which is thought to mediate cellular resistance to EGCG.[28]

Although metformin has many targets in tumor tissue, its anti-cancer effects mainly function by activating the AMP-activated protein kinase/mammalian target of rapamycin (AMPK/mTOR) signaling pathway, which dominantly controls protein synthesis and cell proliferation.[29] Moreover, one of the proposed mechanisms for the anticancer effects of EGCG is by activating AMP-activated protein kinase (AMPK) pathways, as revealed by Wu et al., who demonstrated that EGCG induced apoptosis and terminated cell proliferative impacts. This was accompanied by the up- regulation of AMPK and downregulation of cyclooxygenase-2 (COX-2) and prostaglandin E (2) (PGE 2)' expression.[30] So, the synergistic effect of EGCG and metformin observed in the present study may be explained by their activation of the AMPK signaling pathway, which is a major cellular energy sensor and by their inhibition of the mTOR catalytic activity, which has been proposed as a major driver of cancer proliferation.[29]

Both agents act synergistically to inhibit the laryngeal cancer Hep-2 cell line through suppressing cell proliferation, angiogenesis, ROS production and by promoting apoptosis.

With the results presented in this study, the combination of both EGCG and metformin in treating oral squamous cell carcinoma is recommended as a useful strategy to pursue in future clinical trials.

\section{Limitations of the Study}

Further clinical trials are urgently needed to confirm the potential role of EGCG as an adjunct in cancer therapy.

\section{Conclusion}

EGCG exhibited a synergistic anti-proliferative, antiangiogenic, pro-apoptotic and antioxidant activity on Hep-2 cell line laryngeal carcinoma when combined with metformin. This study revealed that the combination of both EGCG and metformin could be beneficial for the treatment of oral squamous cell carcinoma. This will help researchers to find out the benefits and uses of natural phytochemicals as polyphenols that many researchers were not able to explore. Thus, a new theory on other alternative therapies may be arrived at.

Peer-review: Externally peer-reviewed.

Conflict of Interest: All authors declare that they have no conflict of interest.

Ethics Committee Approval: This study was conducted in accordance with local ethical rules. Ethics committee permission is not required as a cell line was used in this study.

Financial Support: None declared.

Authorship contributions: Concept - N.A., D.S., E.A., W.I., N.A., A.N., N.A.H.; Design - N.A., D.S., E.A., W.I., N.A., A.N., N.A.H.; Supervision - N.A., D.S., E.A., W.I., N.A., A.N., N.A.H.; Funding - N.A., E.A., A.N.; Materials - D.S.; Data collection and/or processing - N.A., E.A., W.I.; Data analysis and/or interpretation - N.A., E.A., W.I.; Literature search - N.A.; Writing - N.A., E.A., W.I.; Critical review - N.A., D.S., E.A., W.I., N.A., A.N., N.A.H. 


\section{References}

1. Yu D, Liu Y, Yang J, Jin C, Zhao X, Cheng J, Liu X, Qi X. Clinical implications of BMI-1 in cancer stem cells of laryngeal carcinoma. Cell Biochem Biophys 2015;71(1):261-9.

2. Guzel E, Karatas OF, Ozgurses ME, Ozen M. New Insights into Laryngeal Squamous Cell Carcinoma: Cancer Stem-Like Cells. Cancer Research Frontiers 2015;1(2):138-48.

3. Wan G, Zhou L, Xie M, Chen H, Tian J. Characterization of side population cells from laryngeal cancer cell lines. Head Neck 2010;32(10):1302-9.

4. Mukhtar E, Adhami VM, Khan N, Mukhtar H. Apoptosis and autophagy induction as mechanism of cancer prevention by naturally occurring dietary agents. Curr Drug Targets 2012;13(14):1831-41.

5. Bodhade AS, Dive AM. Chemoprevention of premalignant and malignant lesions of oral cavity: Recent trends. Eur J Dent 2013;7(2):246-50.

6. Ho YC, Yang SF, Peng CY, Chou MY, Chang YC. Epigallocatechin-3-gallate inhibits the invasion of human oral cancer cells and decreases the productions of matrix metalloproteinases and urokinase-plasminogen activator. J Oral Pathol Med 2007;36(10):588-93.

7. Gu Q, Hu C, Chen Q, Xia Y, Feng J, Yang H. Prevention of chinese green tea on 3,4-benzopyrene-induced lung cancer and its mechanism in animal mode. Zhongguo Fei Ai Za Zhi 2008;11(4):519-23.

8. Lee UL, Choi SW. The chemopreventive properties and therapeutic modulation of green tea polyphenols in oral squamous cell carcinoma. ISRN Oncol 2011;2011:403707.

9. Braicu C, Ladomery MR, Chedea VS, Irimie A, Berindan-Neagoe I. The relationship between the structure and biological actions of green tea catechins. Food Chem 2013;141(3):3282-9.

10. Saini N, Yang X. Metformin as an anti-cancer agent: actions and mechanisms targeting cancer stem cells. Acta Biochim Biophys Sin (Shanghai) 2018;50(2):13343.

11. Sandulache VC, Hamblin JS, Skinner HD, Kubik MW, Myers JN, Zevallos JP. Association between metformin use and improved survival in patients with laryngeal squamous cell carcinoma. Head Neck 2014;36(7):1039-43.

12. Sikka A, Kaur M, Agarwal C, Deep G, Agarwal R. Metformin suppresses growth of human head and neck squamous cell carcinoma via global inhibition of protein translation. Cell Cycle 2012;11(7):1374-82.

13. Yasmeen A, Beauchamp MC, Piura E, Segal E, Pollak $\mathrm{M}$, Gotlieb WH. Induction of apoptosis by metformin in epithelial ovarian cancer: involvement of the Bcl-2 family proteins. Gynecol Oncol 2011;121(3):492-8.
14. Jalving M, Gietema JA, Lefrandt JD, de Jong S, Reyners AK, Gans RO, et al. Metformin: taking away the candy for cancer? Eur J Cancer 2010;46(13):2369-80.

15. Rattan R, Graham RP, Maguire JL, Giri S, Shridhar V. Metformin suppresses ovarian cancer growth and metastasis with enhancement of cisplatin cytotoxicity in vivo. Neoplasia 2011;13(5):483-91.

16. Grivennikov S, Karin M. Autocrine IL-6 signaling: a key event in tumorigenesis?. Cancer Cell 2008;13(1):7-9.

17. Nath N, Khan M, Paintlia MK, Singh I, Hoda MN, Giri S. Metformin attenuated the autoimmune disease of the central nervous system in animal models of multiple sclerosis. J Immunol 2009;182(12):8005-14.

18. Isoda K, Young JL, Zirlik A, MacFarlane LA, Tsuboi $\mathrm{N}$, Gerdes N, et al. Metformin inhibits proinflammatory responses and nuclear factor-kappaB in human vascular wall cells. Arterioscler Thromb Vasc Biol 2006;26(3):611-7.

19. Murakami C, Hirakawa Y, Inui H, Nakano Y, Yoshida H. Effect of tea catechins on cellular lipid peroxidation and cytotoxicity in HepG2 cells. Biosci Biotechnol Biochem 2002;66(7):1559-62.

20. Algire C, Moiseeva O, Deschênes-Simard X, Amrein L, Petruccelli L, Birman E, et al. Metformin reduces endogenous reactive oxygen species and associated DNA damage. Cancer Prev Res (Phila) 2012;5(4):536-43.

21. Rahman AA, Makpol S, Jamal R, Harun R, Mokhtar $\mathrm{N}$, Ngah WZ. Tocotrienol-rich fraction, [6]-gingerol and epigallocatechin gallate inhibit proliferation and induce apoptosis of glioma cancer cells. Molecules 2014;19(9):14528-41.

22. Somers-Edgar TJ, Scandlyn MJ, Stuart EC, Le Nedelec MJ, Valentine SP, Rosengren RJ. The combination of epigallocatechin gallate and curcumin suppresses ER alpha-breast cancer cell growth in vitro and in vivo. Int J Cancer 2008;122(9):1966-71.

23. Toden S, Tran HM, Tovar-Camargo OA, Okugawa Y, Goel A. Epigallocatechin-3-gallate targets cancer stemlike cells and enhances 5-fluorouracil chemosensitivity in colorectal cancer. Oncotarget 2016;7(13):16158-71.

24. Saldanha SN, Kala R, Tollefsbol TO. Molecular mechanisms for inhibition of colon cancer cells by combined epigenetic-modulating epigallocatechin gallate and sodium butyrate. Exp Cell Res 2014;324(1):40-53.

25. Roomi MW, Ivanov V, Kalinovsky T, Niedzwiecki A, Rath M. Anti-tumor effect of ascorbic acid, lysine, proline, arginine, and epigallocatechin gallate on prostate cancer cell lines PC-3, LNCaP, and DU145. Res Commun Mol Pathol Pharmacol 2004;115-116:251-64.

26. Hagen RM, Chedea VS, Mintoff CP, Bowler E, Morse HR, Ladomery MR. Epigallocatechin-3-gallate promotes apoptosis and expression of the caspase 9a splice variant in PC3 prostate cancer cells. Int J Oncol 2013;43(1):194-200. 
27. Wu H, Xin Y, Xiao Y, Zhao J. Low-dose docetaxel combined with (-)-epigallocatechin-3-gallate inhibits angiogenesis and tumor growth in nude mice with gastric cancer xenografts. Cancer Biother Radiopharm 2012;27(3):204-9.

28. Yu C, Jiao Y, Xue J, Zhang Q, Yang H, Xing L, et al. Metformin Sensitizes Non-small Cell Lung Cancer Cells to an Epigallocatechin-3-Gallate (EGCG) Treatment by Suppressing the Nrf2/HO-1 Signaling Pathway. Int J Biol Sci 2017;13(12):1560-9.
29.Zhang T, Wang X, He D, Jin X, Guo P. Metformin sensitizes human bladder cancer cells to TRAIL-induced apoptosis through mTOR/S6K1-mediated downregulation of c-FLIP. Anticancer Drugs 2014;25(8):88797.

30. Wu CH, Ho YS, Tsai CY, Wang YJ, Tseng H, Wei PL, et al. In vitro and in vivo study of phloretin-induced apoptosis in human liver cancer cells involving inhibition of type II glucose transporter. Int J Cancer 2009;124(9):2210-9. 